
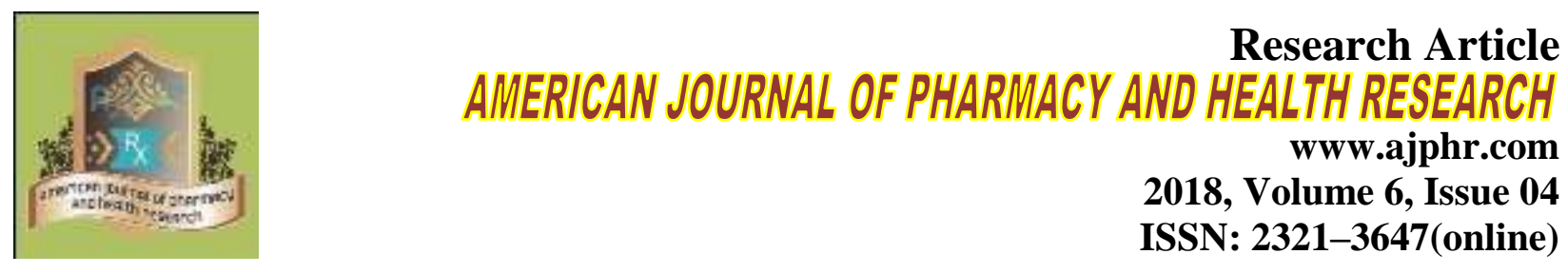

\title{
Design, Development and Evaluation of Amlodipine Besylate IR and Metformin HCI SR Bilayer Floating System.
}

\author{
Susomya Mahapatra ${ }^{1}$, Amiyakanta Mishra ${ }^{1}$, Bijay Ku. Sahoo ${ }^{1 *}$ \\ 1.PG Dept. of Pharmaceutics, College of Pharmaceutical Sciences, Puri-Konark Marine Drive
}

Road, Baliguali, Puri, Odisha, 752002

\begin{abstract}
The scenario of pharmaceutical drug delivery is rapidly changing. Conventional pharmaceutical dosage forms are being replaced by new drug delivery systems. These new drug delivery systems are having border over conventional ones in terms of many biopharmaceutical parameters. One such drug delivery system is bilayer floating sustained release drug delivery system. The research envisaged in the present study is an attempt towards developing a formulation of antidiabetics and anti-hypertensive drug in a single dosage form. The main aim of present study is to formulate and evaluate bilayer tablets of Amlodipine Besylate as IR and Metformin Hydrochloride SR combination tablets for effective treatment of type II diabetes mellitus and hypertension. Preformulation studies including drug excipient compatibility were conducted for both drugs. Different formulations of sustained release, floating Metformin $\mathrm{HCl}$ tablets were prepared by using hydrophilic polymers like HPMC K100M, HPMC K4M etc., were evaluated. Amlodipine immediate release formulations were prepared using sodium starch glycolate as superdisintegrant and starch as disintegrant and were evaluated. Based on the in vitro dissolution data F6 and F3 were selected as the best formulations from Metformin and Amlodipine formulations respectively. From the bilayer tablet Amlodipine layer disintegrated within 5min , Metformin layer started floating after $5 \mathrm{~min}$ and showed total floating time $>12 \mathrm{hrs}$ with good swelling index, good post compression parameters. In vitro dissolution study of bilayer tablet was done in USP type II along with UV spectrophotometer bestowed cumulative \% drug release of Amlodipine as $98.75 \%$ at $30 \mathrm{~min}$ and $99.32 \%$ of Metformin at $12 \mathrm{hrs}$. From the study it was found that, HPMC K100M showed good sustained release for $12 \mathrm{hrs}$. Among the disintegrants used sodium starch glycolate and starch showed good disintegration of Amlodipine layer. Overall this FDC formulation could be more effective, convenient \& patient compliance.
\end{abstract}

Keywords: Amlodipine Besylate (AMB), Metformin Hydrochloride(MFH), Sodium starch glycolate, FDC,HPMC K100M, HPMC K4M.

*Corresponding Author Email: dr.sahoo14@gmail.com

Received 15 March 2018, Accepted 20 March 2018

Please cite this article as: Sahoo BK et al., Design, Development and Evaluation of Amlodipine Besylate IR and Metformin HCl SR Bilayer Floating System. American Journal of Pharmacy \& Health Research 2018. 


\section{INTRODUCTION}

Floating drug delivery systems is one of the most leading methodologies in gastro retentive drug formulations. The oral route is the most preferred route of administration of drugs because of low cost of therapy, ease of administration, patient compliance and flexibility in formulation etc. But this is difficult due to number of physiological problems as fluctuations in gastric emptying process, narrow absorption window and stability problem in intestine. These considerations lead to development of unique oral controlled release dosage forms with gastro retentive properties ${ }^{[1-}$ 4]. With many drugs, the basic goal of therapies to achieve a steady-state blood level or tissue level that is therapeutically effective and non toxic for an extended period of time ${ }^{[5-6]}$

Floating drug delivery systems (FDDS) or hydro dynamically controlled systems are a lowdensity system that have sufficient buoyancy to float over the gastric contents and remain buoyant in the stomach without affecting the gastric emptying rate for a prolonged period of time and is expected to give better bio availability, reduce drug wastage, improves solubility of drugs that are less soluble in a high PH environment ${ }^{[6-8]}$.

Diabetes is one of the most prevailing and advancing diseases in the world having affected 6.6\% of the world population. Metformin hydrochloride is the most widely used oral Anti Diabetic drug in the world. Metformin shows high aqueous solubility and low cell membrane permeability [4]. The usual dosage for Metformin is $250-500 \mathrm{mg} 3-4$ times daily. The absolute bioavailability of Metformin hydrochloride is 50-60\% and is having short biological half-life of 6.2 hrs. A conventional oral sustained release formulation releases most of the drug content at colon. Since Metformin has absorption window in stomach \& upper part of GIT up to intestine, there is a need to develop gastro retentive sustained release formulation. ${ }^{[9-11]}$.

Amlodipine is long acting calcium channel blocker and used in the treatment of hypertension, and chronic stable angina. In hypertension or angina, initially $5 \mathrm{mg}$. one daily and adjusted to maximum dose $10 \mathrm{mg}$ one daily dose of Amlodipine is given orally. Amlodipine has maximum solubility in acidic pH. Amlodipine has some adverse effect such as nausea, abdominal pain. Amlodipine besylate as immediate layer retain in stomach improves solubility, bioavailability, reduces drug waste and decrease side effect such as gastric irritation and nausea.

The aim of present work is to formulate and evaluate bilayer tablets of Metformin Hydrochloride and Amlodipine Besylate as fixed dose combination tablets for effective treatment of type II diabetes mellitus and for hypertension. This drug delivery is attempted to maintain time depended constant, effective drug level in the body with concomitant 
minimization of undesired side-effects. The study envisages for development of a bilayer floating tablet $\&$ to increase the efficiency of the drug providing sustained action for the treatment of the diabetics and hypertension in a single dosage form.

\section{MATERIALS AND METHOD}

Amlodipine besylate was received as a gift sample from Macro lab Sikkim pvt. Ltd., Metformin hydrochloride was received from Macro lab Sikkim pvt. Ltd., Hydroxy Propyl Methyl Cellulose K100M, K4M, guar gum, sodium CMC, Sodium starch glycolate were purchased from Lab Chemical, Bhubaneswar and other excipients were available in college of pharmaceutical sciences, Puri laboratory.

\section{Preparation of bilayer floating tablet (BFT)}

The prepared granules of both the layers were compressed on a Rotary lab press II of Karnavati Engineering Ltd. on $19 / 8.5 \mathrm{~mm}$ Round shaped punch. The hardness was $5.2 \mathrm{~kg} / \mathrm{cm}^{2}$ and the tablet thickness was $3.1 \mathrm{~mm}$. Both the prepared granules came from two different hoppers to two different feed frames where they occupied the die cavity. The bottom layer was first compressed with lower pressure, which was then followed by filling of the die cavity by the upper layer granules. The final compression was done only after both the granules occupied the die cavity one on top of the other. Both the layers were identified on the basis of color since the immediate release layer had pink color and the sustain release layer has white color.

Table 1: Composition of Floating matrix Layer Containing Metformin hydrochloride

\begin{tabular}{llllllllll}
\hline & $\begin{array}{l}\text { F1 } \\
(\mathbf{m g}))\end{array}$ & $\begin{array}{l}\text { F2 } \\
(\mathbf{m g})\end{array}$ & $\begin{array}{l}\text { F3 } \\
(\mathbf{m g})\end{array}$ & $\begin{array}{l}\text { F4 } \\
(\mathbf{m g})\end{array}$ & $\begin{array}{l}\text { F5 } \\
(\mathbf{m g}))\end{array}$ & $\begin{array}{l}\text { F6 } \\
(\mathbf{m g})\end{array}$ & $\begin{array}{l}\text { F7 } \\
(\mathbf{m g})\end{array}$ & $\begin{array}{l}\text { F8 } \\
(\mathbf{m g})\end{array}$ & $\begin{array}{l}\text { F9 } \\
(\mathbf{m g})\end{array}$ \\
\hline Metformin HCL & 500 & 500 & 500 & 500 & 500 & 500 & 500 & 500 & 500 \\
HPMCK100 & - & - & - & - & - & 160 & - & - & 120 \\
HPMCK4 & 160 & 80 & 120 & - & - & - & - & - & - \\
GUAR GUM & - & - & - & 160 & - & - & 120 & - & - \\
SOD. CMC & - & - & - & - & 160 & - & - & 120 & - \\
PVPK30 & 40 & 40 & 40 & 40 & 40 & 40 & 40 & 40 & 40 \\
MCC & 80 & 80 & 80 & 80 & 80 & 80 & 80 & 80 & 80 \\
Ethyl cellulose & - & 80 & 40 & - & - & - & 40 & 40 & 40 \\
Sod. Bicarbonate & 80 & 80 & 80 & 80 & 80 & 80 & 80 & 80 & 80 \\
Talc & 10 & 10 & 10 & 10 & 10 & 10 & 10 & 10 & 10 \\
Mag.stearate & 10 & 10 & 10 & 10 & 10 & 10 & 10 & 10 & 10 \\
Total & 880 & 880 & 880 & 880 & 880 & 880 & 880 & 880 & 880 \\
\hline
\end{tabular}

Table 2: Composition of Immediate Layer Containing Amlodipine besylate

\begin{tabular}{lllll}
\hline & F1(mg) & F2(mg) & F3(mg) & F4(mg) \\
\hline Amlodipine Besylate & 5 & 5 & 5 & 5 \\
MCC & 92.5 & 92.5 & 92.5 & 92.5 \\
SSG & 30 & 30 & 15 & - \\
\hline
\end{tabular}




\begin{tabular}{lllll}
\hline STARCH & - & - & 15 & 30 \\
PVPK30 & 7.5 & 15 & 7.5 & 7.5 \\
Talc & 7.5 & 7.5 & 7.5 & 7.5 \\
Mg. Stearate & 7.5 & 7.5 & 7.5 & 7.5 \\
Iron oxide & q.s & q.s & q.s & q.s \\
Total & 150 & 150 & 150 & 150 \\
\hline
\end{tabular}

\section{PRE - FORMULATION STUDIES:}

\section{Compatibility studies by FTIR}

Compatibility must be established between the active ingredient and other excipients to produce a stable, efficacious, attractive and safe product. So before producing the actual formulation, compatibility of Amlodipine besylate and Metformin $\mathrm{HCl}$ with polymers and other excipients were tested using the Fourier Transform Infrared Spectroscopy (FTIR)

\section{PRE - COMPRESSION PARAMETERS:}

\section{Angle of Repose:}

The angles of repose of the granules were determined by using funnel method. The accurately weighted granules were taken in a funnel. The height of the funnel was adjusted in such a way that the tip of the funnel just touched the apex of the heap of the granules. The diameter of the powder cone was measured and angle of repose was calculated by using the equation (Table $3 \&$ 4)

$$
\operatorname{Tan} \theta=h / \mathbf{r} \text { or } \theta=\tan ^{-1} h / r
$$

Where, $\mathrm{h}=$ the height and radius of the powder cone.

Bulk density determination :( Table 3 \& 4)

Tapped density determination:

Carr's Index or Compressibility index

Hausner's ratio:

\section{POST- COMPRESSION PARAMETERS}

\section{Uniformity of weight (Weight variation test)}

The weight variation test would be a satisfactory method for determining drug content uniformity of drug distribution. 20 tablets were weighed individually and collectively. Average weight was calculated from the total weight of all tablets. The individual weights were compared with the average weight ${ }^{[8]}$. The percent deviation was calculated using the following formula (table 5)

$\%$ Deviation $=$ Individual weight - Average weight $/$ Average weight $\mathrm{x} 100$

\section{Hardness test:}


Tablet hardness is the force necessary to break the tablet diametrically. Hardness is sometimes termed the tablet crushing strength. The tablet should be stable to mechanical stress during handling and transportation. The hardness was tested using Monsanto hardness tester. The average of the five determinations was determined and reported. (Table 5)

\section{Thickness:}

The thickness of individual tablets is measured with a micrometer, which gives us information about the variation between tablets. The thickness of the tablets was measured by Digital Vernier Caliper. It is expressed in mm. (table 5)

\section{Friability (F):}

It is a measure of tablet strength. The friability of the tablet was determined using Roche Friabilator. It is expressed in \%. 10 tablets were initially weighed and transferred into the friabilator. The friabilator was operated at $25 \mathrm{rpm}$ for 4 mins. The tablets were weighed again. Friability of tablet should not exceed 1\%. (Table 5)

\section{Disintegration test for IR:}

The fragmentation of tablet into small fragments or granules is called disintegration. The time taken for disintegration is determined by disintegration apparatus. The machine is operated at 2832 cycles/min through a distance of 50-60 mm. place 6 tablets in apparatus (i.e., in tubes of basket), add disc to each tube and operate the apparatus. At the end of the $15 \mathrm{~min}$ all the tablets should disintegrate, completely without leaving any residue in the basket. (Table 6)

\section{Drug content:}

Metformin: Five tablets were weighed and powdered. The quantity of powder blend equivalent to $500 \mathrm{mg}$ of metformin $\mathrm{HCl}$ was weighed accurately and taken in $250 \mathrm{ml}$ volumetric flask. To it $150 \mathrm{ml}$ of $0.1 \mathrm{~N} \mathrm{HCl}$ was added and sonicated for 5 minutes. The volume was made up to $250 \mathrm{ml}$ with $0.1 \mathrm{~N} \mathrm{HCl}$ and filtered. From the above solution, $1 \mathrm{ml}$ was diluted to $50 \mathrm{ml}$ with $0.1 \mathrm{~N} \mathrm{HCl}$. The drug content was determined spectrophotometrically at 233nm. (Table 5).

Amlodipine: Five tablets were weighed and powdered. The quantity of powder blend equivalent to $100 \mathrm{mg}$ of amlodipine besylate was weighed accurately and taken in $100 \mathrm{ml}$ volumetric flask. The solution was filtered. After a suitable dilution with $0.1 \mathrm{~N} \mathrm{HCl}$ the drug content was determined by UV spectrophotometrically at 235nm. (Table 6)

\section{In-vitro dissolution studies:}

The drug release from floating IR layer were studied by the in vitro dissolution studies using USP II paddle apparatus at a speed of $100 \mathrm{rpm}$ using $0.1 \mathrm{NHCl}(1.2 \mathrm{pH})$ with a volume of $900 \mathrm{ml}$ at a temperature of $37^{\circ} \mathrm{C} \pm 0.5^{\circ} \mathrm{C}($ Table. 10$)$. 


\section{Evaluation of Floating Layer}

\section{Swelling index:}

The individual tablets were weighted accurately and kept in $200 \mathrm{ml}$ of $0.1 \mathrm{~N} \mathrm{HCl}$. Tablets were taken out carefully after each hour upto 6hours, blotted with filter paper to remove the water present on the surface and weighed accurately. Percentage swelling (swelling index) was calculated by using following formula.(Table.7)

WU $\%=$ Weight of swollen tablet - initial weight of the tablet/ initial weight of the tablet $\times 100$

\section{In-vitro-buoyancy studies:}

The in- vitro buoyancy was determined by floating lag time. The tablets were placed in a $200 \mathrm{ml}$ beaker containing $0.1 \mathrm{~N} \mathrm{HCl}$. The time required for the tablet to rise to the surface and float was taken as the floating lag time(Table.8).

\section{In-vitro dissolution studies:}

The drug release from floating bilayer tablets can be studied by the in vitro dissolution studies using USP II paddle apparatus at a speed of $100 \mathrm{rpm}$ using $0.1 \mathrm{NHCl}(1.2 \mathrm{pH})$ with a volume of $900 \mathrm{ml}$ at a temperature of $37^{\circ} \mathrm{C} \pm 0.5^{\circ} \mathrm{C}$. (Table 9).

\section{Kinetic modeling of drug release:}

To examine the drug release kinetics and mechanism, the cumulative release data were fitted to models representing zero order $(\mathrm{Q} v / \mathrm{s} t)$, first order $\left[\log \left(\mathrm{Q}_{\mathrm{O}}-\mathrm{Q}\right) \mathrm{v} / \mathrm{s} \mathrm{t}\right]$, Higuchi's square root of time ( $\mathrm{Q} v / \mathrm{s} \mathrm{t}^{1 / 2}$ ) and korsemeyer Peppas double $\log$ plot ( $\log \mathrm{Q}$ v/s $\log \mathrm{t}$ ) respectively, where $\mathrm{Q}$ is the cumulative percentage of drug released at time $t$ and $\left(Q_{0}-Q\right)$ is the cumulative percentage of drug remaining after time $\mathrm{t}$.

\section{RESULTS AND DISCUSSION}

Calibration curves of Metformin and Amlodipine:

Table A: Standard graph values for Metformin HCl

\begin{tabular}{ll}
\hline Conc. & $\begin{array}{l}\text { Metformin HCl } \\
\text { Abs. }\end{array}$ \\
\hline 2 & 0.329 \\
4 & 0.523 \\
6 & 0.757 \\
8 & 0.951 \\
10 & 1.209 \\
\hline
\end{tabular}




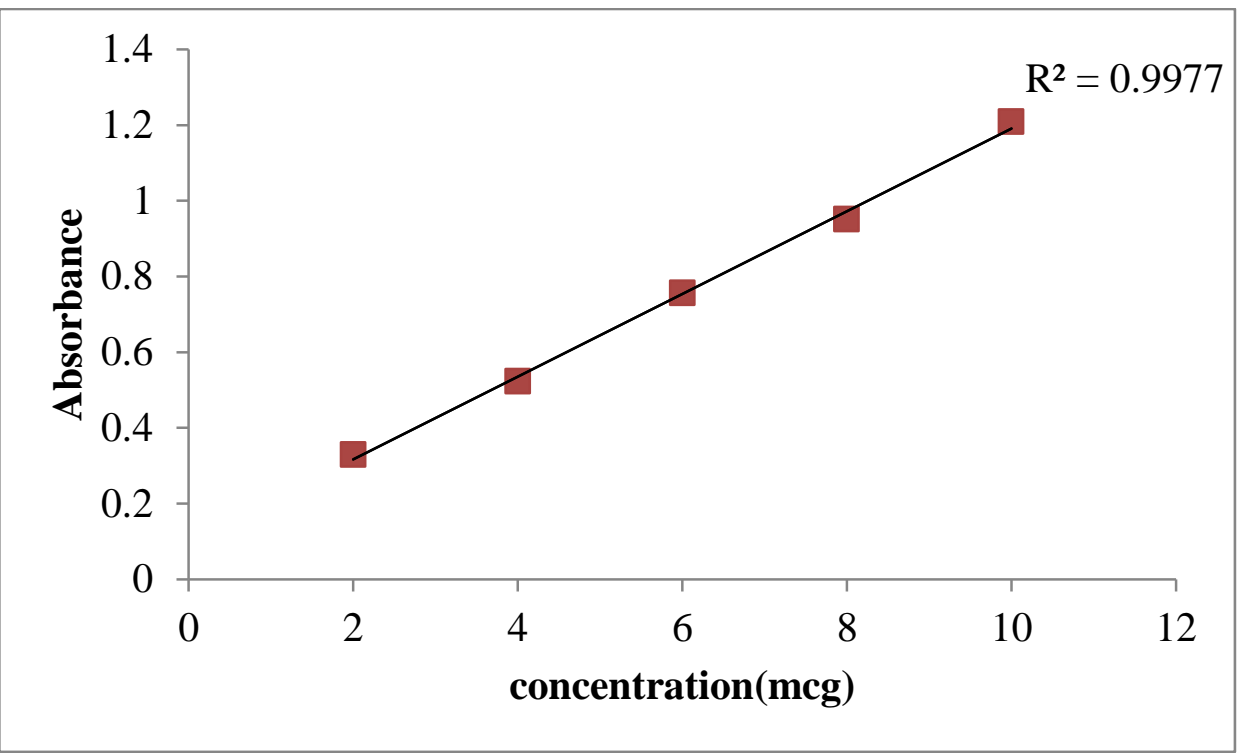

Figure: 1Calibration curve of Metformin $\mathrm{HCl}$ in distilled water

Table B. Standard graph values for Amlodipine besylate

\begin{tabular}{ll}
\hline Amlodipine besylate & \\
Conc. & Abs. \\
\hline 5 & 0.280 \\
10 & 0.493 \\
15 & 0.823 \\
20 & 1.295 \\
25 & 1.484 \\
\hline
\end{tabular}

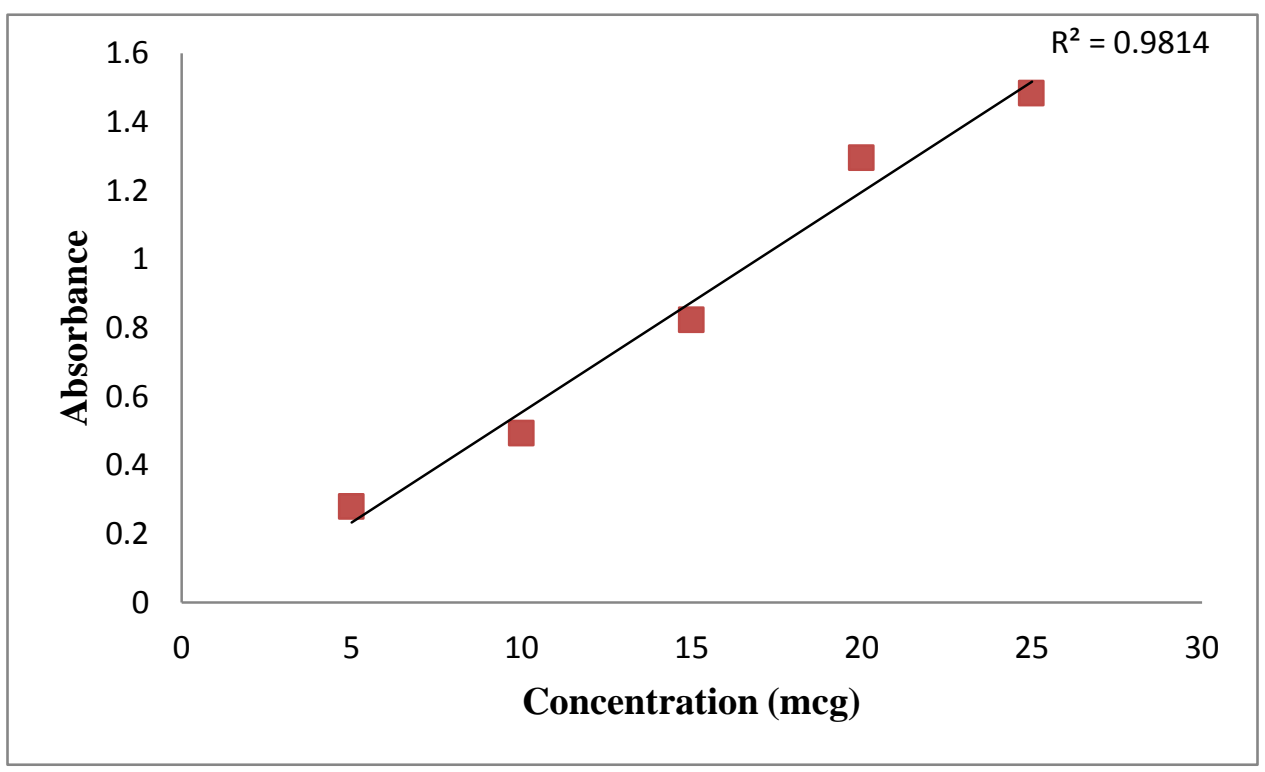

Figure 2: Calibration curve of Amlodipine besylate in methanol

Calibration curve of metformin $\mathrm{HCl}$ and amlodipine besylate was constructed using water and methanol as the medium. Graph was plotted by taking concentration on $\mathrm{x}$-axis and absorbance on y-axis. 


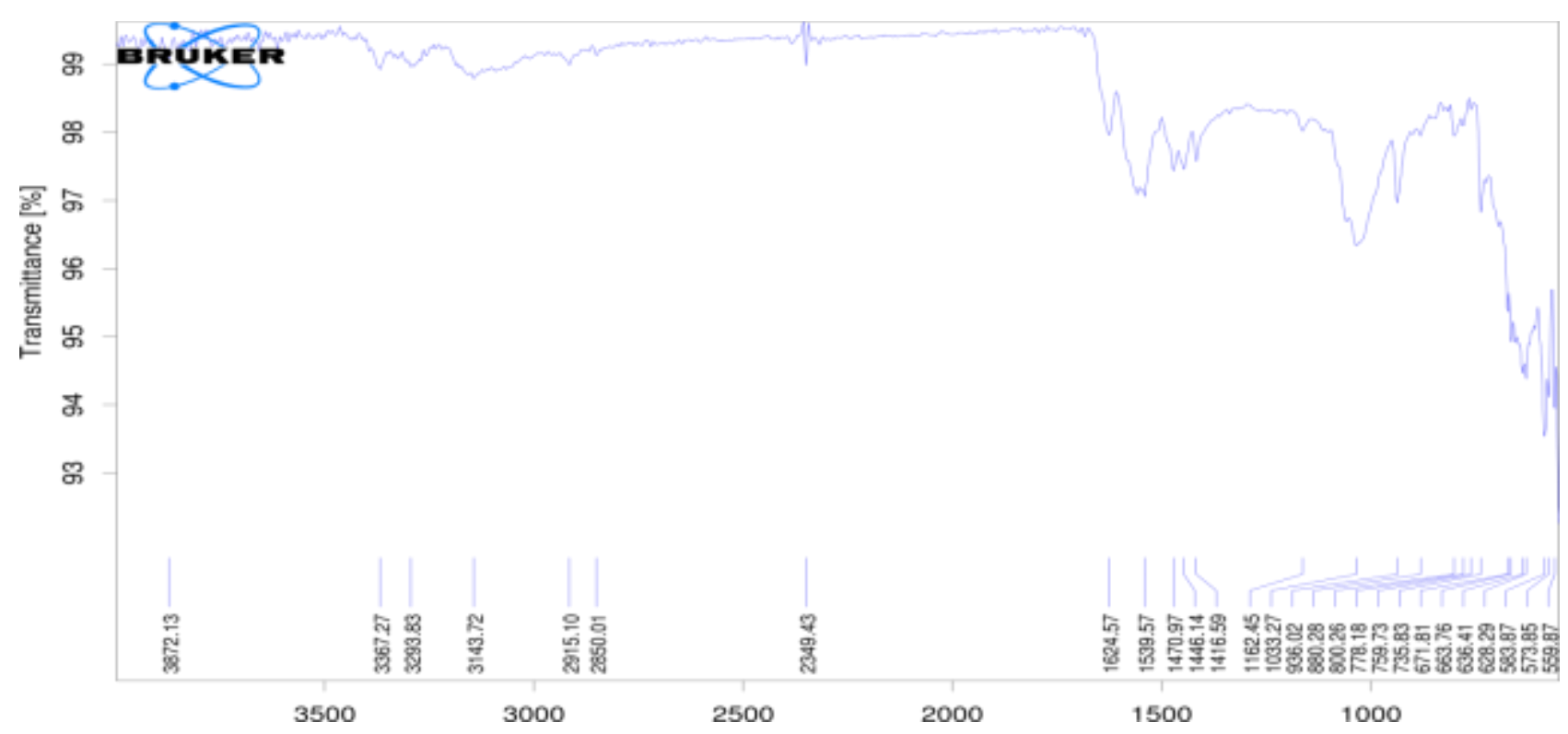

E:IFTIR DATA\FILES \Metformin $\mathrm{HCl}+$ Excipients (Physical mixture) Instrument type and $24 / 11 / 17$

Figure 3 i: FT-IR graph for Metformin HCl optimized formulation(Physical Mixture)

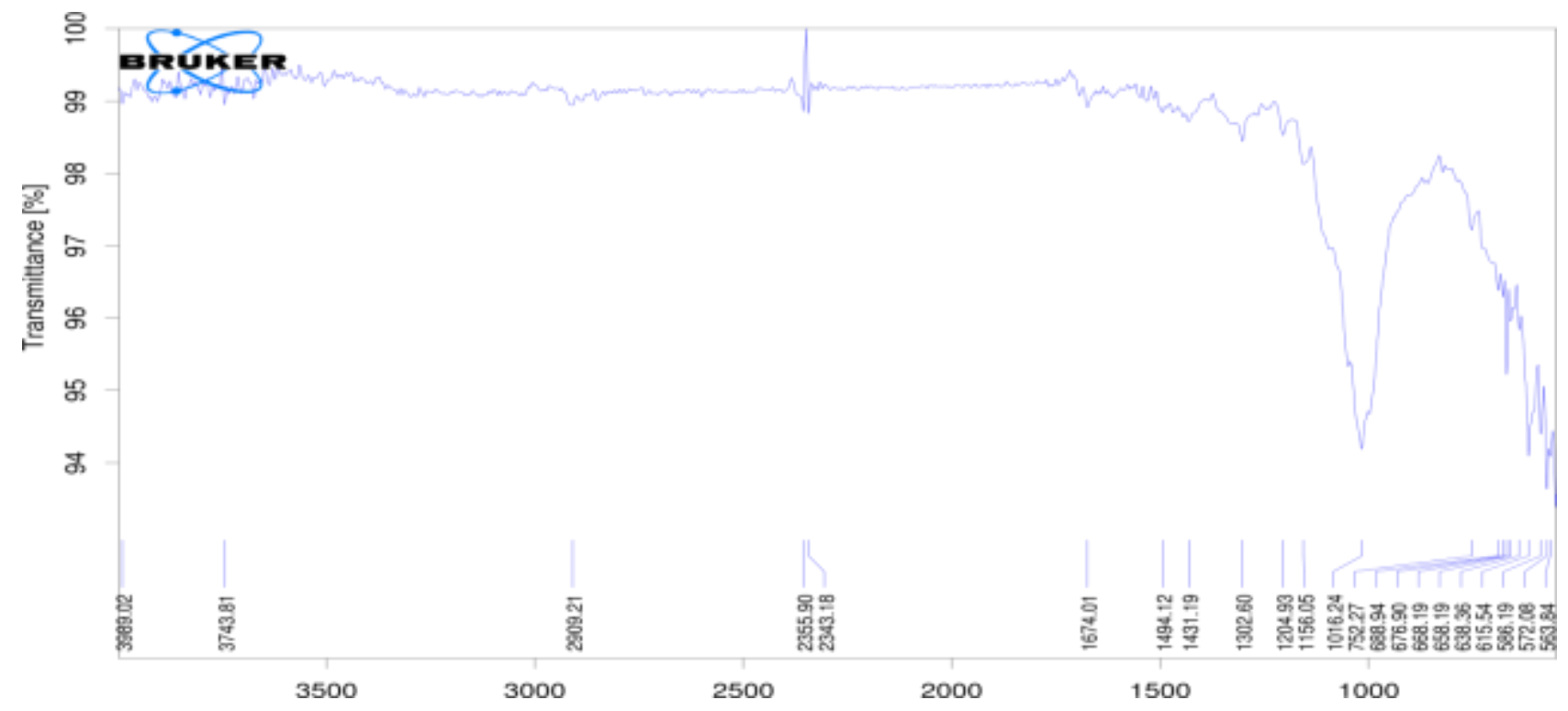

E:IFTIR DATA\FILE Amlodipine besylate + Excipients (Physical mixture) Instrument type and 24/11/17

Figure 3 ii: FT-IR graph for Amlodipine besylate optimized formulation (Physical Mixture)

Evaluation for Pre-compression parameters 
Table 3: Pre compression data of SR layer

\begin{tabular}{llllllllll}
\hline Sl.no. & F1 & F2 & F3 & F4 & F5 & F6 & F7 & F8 & F9 \\
\hline Angle of repose & 35.2 & 33.0 & 32.4 & 32.02 & 35.1 & 31.5 & 32.6 & 35.0 & 32.3 \\
Bulk Density $(\mathrm{g} / \mathrm{ml})$ & 0.575 & 0.572 & 0.582 & 0.560 & 0.577 & 0.583 & 0.577 & 0.560 & 0.573 \\
Tapped Density $(\mathrm{g} / \mathrm{ml})$ & 0.654 & 0.655 & 0.669 & 0.665 & 0.675 & 0.66 & 0.664 & 0.656 & 0.658 \\
Carr's index & 12.07 & 12.67 & 13.00 & 11.72 & 14.51 & 11.66 & 13.10 & 14.63 & 12.91 \\
Hausner's ratio & 1.13 & 1.14 & 1.14 & 1.13 & 1.16 & 1.13 & 1.15 & 1.17 & 1.14 \\
\hline
\end{tabular}

Table 4: Pre compression data of IR layer

\begin{tabular}{lllll}
\hline SL.NO. & F1 & F2 & F3 & F4 \\
\hline Angle of repose & 32.42 & 34.36 & 32.86 & 33.81 \\
Bulk Density (g/ml) & 0.578 & 0.61 & 0.596 & 0.571 \\
Tapped Density $(\mathrm{g} / \mathrm{ml})$ & 0.655 & 0.697 & 0.678 & 0.666 \\
Carr's index & 1.133 & 1.142 & 1.137 & 1.166 \\
Hausner's ratio & 11.75 & 12.48 & 12.09 & 14.261 \\
\hline
\end{tabular}

Evaluation for Post compression parameters:

Table 5: Post compression Studies of Bilayer tablets

\begin{tabular}{llllll}
\hline Sl.no. & $\begin{array}{l}\text { \%Weight } \\
\text { Variation }\end{array}$ & $\begin{array}{l}\text { Hardness } \\
\left(\mathbf{K g} / \mathbf{c m}^{2}\right)\end{array}$ & $\begin{array}{l}\text { Thickness } \\
(\mathbf{m m})\end{array}$ & Friability $(\%)$ & $\begin{array}{l}\text { Drug Content } \\
\text { of SR Layer }\end{array}$ \\
\hline F1 & $1.02 \pm 0.80$ & $5.12 \pm 0.044$ & $6.92 \pm 0.20$ & $0.77 \pm 0.054$ & $99.69 \pm 0.044$ \\
F2 & $1.02 \pm 0.531$ & $5.08 \pm 0.044$ & $6.76 \pm 0.250$ & $0.63 \pm 0.054$ & $99.25 \pm 0.07$ \\
F3 & $1.01 \pm 0.836$ & $5.16 \pm 0.054$ & $6.90 \pm 0.089$ & $0.66 \pm 0.044$ & $98.8 \pm 0.07$ \\
F4 & $1.03 \pm 0.547$ & $5.08 \pm 0.054$ & $6.92 \pm 0.109$ & $0.68 \pm 0.044$ & $99.69 \pm 0.044$ \\
F5 & $1.00 \pm 0.80$ & $5.28 \pm 0.044$ & $6.90 \pm 0.089$ & $0.80 \pm 0.044$ & $98.41 \pm 0.083$ \\
F6 & $1.03 \pm 0.547$ & $5.16 \pm 0.089$ & $6.92 \pm 0.088$ & $0.68 \pm 0.70$ & $99.47 \pm 0.044$ \\
F7 & $1.02 \pm 0.836$ & $5.22 \pm 0.054$ & $6.76 \pm 0.109$ & $0.62 \pm 0.044$ & $99.25 \pm 0.070$ \\
F8 & $1.01 \pm 0.894$ & $5.18 \pm 0.044$ & $6.90 \pm 0.089$ & $0.55 \pm 0.044$ & $98.87 \pm 0.054$ \\
F9 & $1.02 \pm 0.836$ & $5.08 \pm 0.089$ & $6.90 \pm 0.089$ & $0.56 \pm 0.083$ & $99.06 \pm 0.083$ \\
\hline
\end{tabular}

Table 6: Drug content and disintegration time of IR tablet

\begin{tabular}{lll}
\hline S1. no. & Drug content of IR layer & Disintegration time(min) \\
\hline F1 & $98.8 \pm 0.07$ & $10 \pm 0.994$ \\
F2 & $98.41 \pm 0.083$ & $12 \pm 0.994$ \\
F3 & $99.24 \pm 0.054$ & $5 \pm 0.894$ \\
F4 & $98.87 \pm 0.087$ & $16 \pm 0.581$ \\
\hline
\end{tabular}

Table 7: Swelling index

\begin{tabular}{llllllll}
\hline Sl no. & 0 hr & 1hr & 2hr & 3hr & 4hr & 5hr & 6hr \\
\hline F1 & 0 & 20.27 & 36.09 & 51.02 & 62.47 & 72.09 & 90.26 \\
F2 & 0 & 26.21 & 45.12 & 59.56 & 73.89 & 85.06 & 95.45 \\
F3 & 0 & 21.56 & 35.46 & 50.02 & 60.24 & 74.02 & 92.80 \\
F4 & 0 & 18.06 & 29.18 & 46.70 & 60.04 & 73.56 & 95.76 \\
F5 & 0 & 32.52 & 45.04 & 64.63 & 79.60 & 92.34 & \\
F6 & 0 & 20.64 & 32.19 & 52.16 & 63.09 & 75.99 & 97.52 \\
F7 & 0 & 22.43 & 44.60 & 55.57 & 72.22 & 85.11 & 94.56 \\
F8 & 0 & 31.52 & 44.23 & 64.63 & 79.60 & 90.02 & \\
F9 & 0 & 19.24 & 30.19 & 49.12 & 62.21 & 74.79 & 96.61 \\
\hline
\end{tabular}


Table 8: In vitro buoyancy studies

\begin{tabular}{lll}
\hline Sl. no. & $\begin{array}{l}\text { Floating Lag } \\
\text { time in } \\
\text { minutes }\end{array}$ & $\begin{array}{l}\text { Floating time in } \\
\text { hours }\end{array}$ \\
\hline F1 & 6 & $>12 \mathrm{hrs}$ \\
F2 & 7 & $10 \mathrm{hrs}$ \\
F3 & 8 & $10 \mathrm{hrs}$ \\
F4 & 4 & $>12 \mathrm{hrs}$ \\
F5 & 15 & $5 \mathrm{hrs}$ \\
F6 & 3 & $>12 \mathrm{hrs}$ \\
F7 & 5 & $>12 \mathrm{hrs}$ \\
F8 & 20 & $6 \mathrm{hrs}$ \\
F9 & 4 & $>12 \mathrm{hrs}$ \\
\hline
\end{tabular}

Table 9: Cumulative \%drug released (\% CDR) formulations of SR layer

\begin{tabular}{llllllllll}
\hline Time(hr) & F1 & F2 & F3 & F4 & F5 & F6 & F7 & F8 & F9 \\
\hline 0 & 0 & 0 & 0 & 0 & 0 & 0 & 0 & 0 & 0 \\
1 & 11.46 & 11.98 & 8.80 & 9.01 & 30.49 & 8.99 & 9.65 & 23.76 & 11.21 \\
2 & 23.22 & 19.11 & 12.06 & 13.01 & 53.8 & 16.03 & 13.32 & 39.44 & 16.02 \\
3 & 34.56 & 26.35 & 20.75 & 21.42 & 74.80 & 23.66 & 26.33 & 59.83 & 25.43 \\
4 & 44.46 & 31.12 & 30.96 & 32.58 & 98.80 & 34.7 & 38.84 & 79.8 & 37.87 \\
5 & 58.92 & 38.76 & 41.81 & 41.81 & & 47.81 & 45.61 & 99.15 & 50.49 \\
6 & 62.1 & 49.17 & 55.39 & 59.51 & & 58.25 & 51.76 & & 64.37 \\
7 & 67.94 & 65.11 & 75.89 & 68.88 & & 66.72 & 59.64 & 69.44 \\
8 & 76.35 & 74.21 & 88.04 & 75.89 & & 74.21 & 64.09 & & 76.19 \\
9 & 82.94 & 86.48 & 98.55 & 88.04 & & 81.19 & 77.45 & 82.04 \\
10 & 95.54 & 96.01 & & 98.55 & & 85.47 & 83.58 & 87.59 \\
11 & & & & & & 92.36 & 97.29 & & 93.15 \\
12 & & & & & & 99.32 & & & 96.08 \\
\hline
\end{tabular}

Table 10: Cumulative \%drug released (\% CDR) formulations of IR layer

\begin{tabular}{lllll}
\hline Time(Mins) & F1 & F2 & F3 & F4 \\
\hline 0 & 0 & 0 & 0 & 0 \\
5 & 14.27 & 24.78 & 24.21 & 21.76 \\
10 & 24.67 & 64.11 & 54.58 & 45.11 \\
15 & 50.24 & 78.37 & 73.82 & 68.74 \\
20 & 74.21 & 86.42 & 84.21 & 82.32 \\
25 & 89.36 & 97.26 & 95.54 & 91.42 \\
30 & & & 98.75 & 96.16 \\
\hline
\end{tabular}




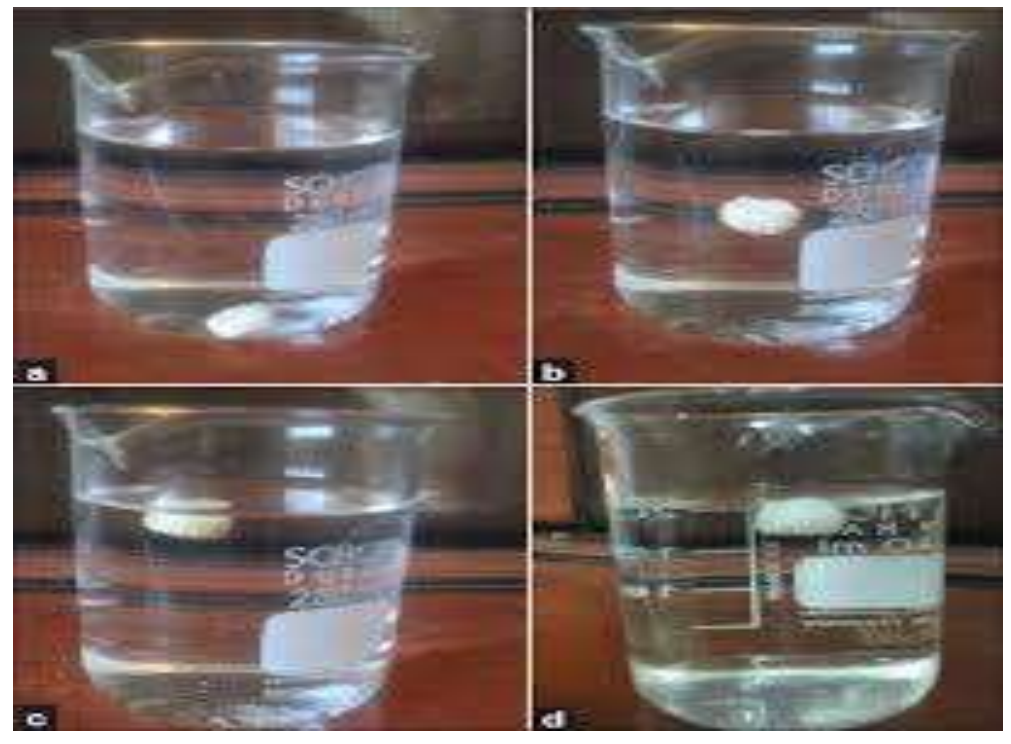

The Real Floating Tablet

Figure 4: In vitro floating lag time of tablet

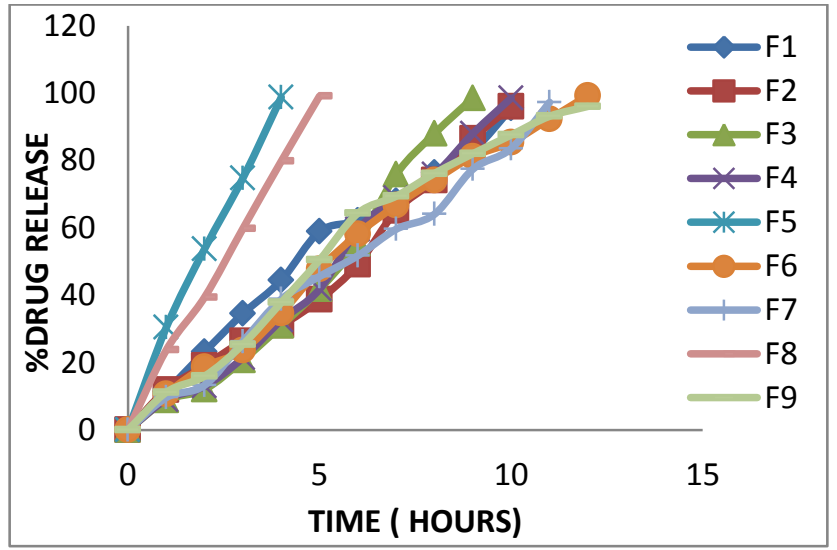

(a)

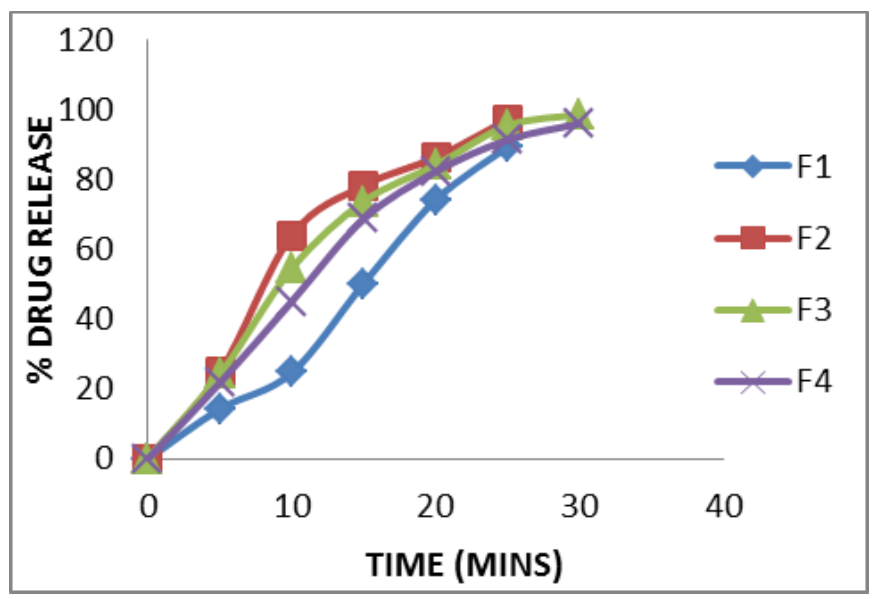

(b)

Figure 5: \% Cumulative drug release of metformin $\mathrm{HCl}$ (a) and amlodipine besylate (b) 
The calibration data \& curves of Metformin $\mathrm{HCl}$ and Amlodipine Besylate are given in Table-A $\&$ B, Fig $1 \& 2$. All the tablets pass the weight variation test as the average \% weight variation was within the pharmacopoeia limit of $7.5 \%$. Weight variation limits are from $1.00 \pm 0.80$.Fig 3(i) \& 3(ii) shows there is no interaction between pure drug and its excipients. The tablet hardness values ranged from $5.08 \pm 0.054 \mathrm{~kg} / \mathrm{cm}^{2}$ for all formulations and were almost same. This indicates good tablet strength. The hardness values limits are from 4 to 10 . The friability values were found to be within the limit (1.0\%) for all the formulations. This indicated good handling property of the prepared tablets. The friability values limits are from $0.56 \pm 0.083$. The tablet thicknesses of all the tablets are ranged from $6.76 \pm 0.109$. The disintegration time for the IR layer is found to be 5 mins. The swelling index of tablets is ranged from 90.26 at 6 hour. \pm 0.12 . The lag time and floating time is found to be $3 \mathrm{mins},>12$ hours. The drug content uniformity values are ranges from 98.8 for SR and 98.41 for IR. (Tables 5, 6, 7, 8)

\section{In -vitro drug release study:}

Dissolution data of formulations of Bi layer Floating Tablets by Paddle method (USP II) are reported in Table $9 \& 10$ Figure 5(a), 5(b). The dissolution profile of amlodipine besylate IR layer was given in graphical representation, the formulation F3 was maximum drug release, hence we conclude that the AMB/F3 was best formula and AMB/F3 IR layer was compressed with Metformin hydrochloride SR layers (MFH/F6).In this dissolution profile the formulation F6 was shown maximum drug release within 12 hours and it shows lag floating time at 5 mins \& sustain of the drug release in Bilayer form up to $12 \mathrm{hrs}$ (Table $9 \&$ Figure $4 \& 5$ (a)). Formulation MFH/ F6 contains HPMC k100m (18\%) shows better in-vitro drug release profile and the other polymers are well in drug release but they not reached in up to $12 \mathrm{hrs}$. (Table 10\& Figure 5(b)) . The in-house prepared bilayer tablets are shown in Figure 6. 


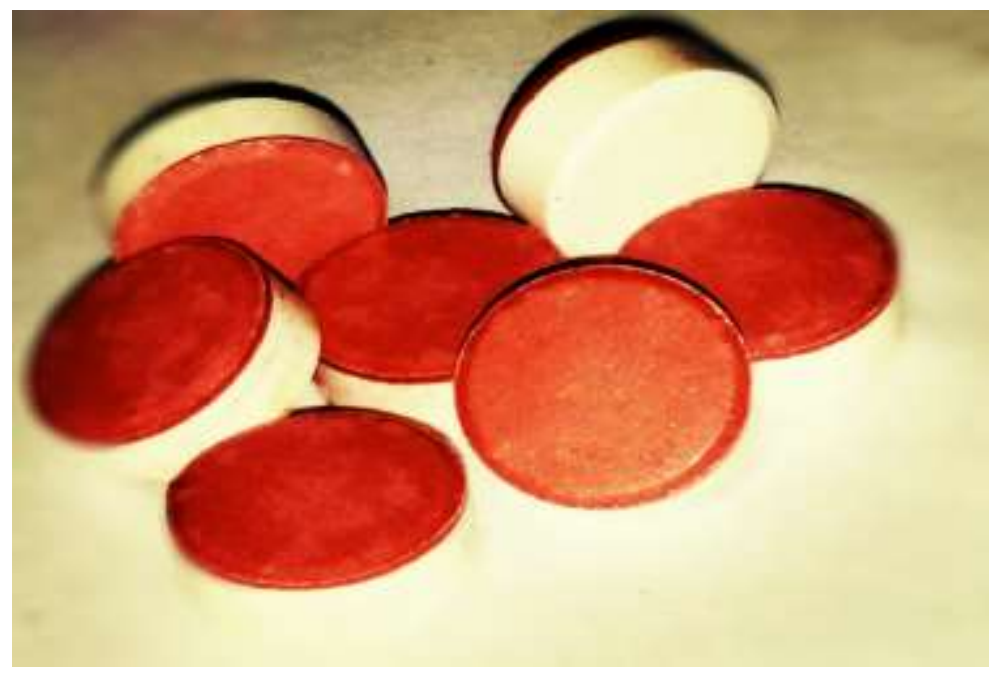

Figure 6: Bilayer FDC Tablet

The study confers the preparation of floating bilayered tablets of Metformin hydrochloride and Amlodipine besylate. The effervescent based floating drug delivery was a promising approach to achieve in-vitro buoyancy of metformin hydrochloride. The addition of gel forming polymer HPMC K 100M, K4M and other polymers and sodium bicarbonate was essential to achieve in vitro buoyancy. The release kinetics of MFH/F6 formulation shows better sustained release i.e 99.32\% within 12 hours as compared to remaining other formulation. Among all formulations AMB/F3 formulation of amlodipine besylate containing starch and sodium starch glycolate showed good disintegration within 5 minutes and of drug release of $98.75 \%$ within $30 \mathrm{mins}$.

\section{CONCLUSION}

From this study by preparing bilayer tablets, it was concluded that we could reduce the total dose, dosage frequency, dose related side effects, and improve the bioavailability of Metformin hydrochloride which in turn improves the patient compliance. Thus, a fixed dose combination tablet of Metformin hydrochloride and amlodipine besylate could be designed as bilayer tablets which will have good patient compliance over their individual marketed counterparts. Moreover, according to our knowledge, this will be first fixed dose combination which is going to available for the Indian diabetics and hypertensive patients community, if it is marketed after some fine tuning of our in-house formulation of Metformin $\mathrm{HCl} 500 \mathrm{mg}$ as SR along with Amlodipine Besylate $5 \mathrm{mg}$ as IR.

\section{Future study}

Future studies can be depicted as follows:

$\checkmark \quad$ In vivo Studies

$\checkmark \quad$ Scale-up studies of the optimized formulation 
$\checkmark \quad$ Bioavailability Studies

$\checkmark \quad$ In vivo-In vitro Correlation (IVIVC)

\section{ACKNOWLEDGEMENT}

Authors are thankful to Prof. (Dr.) A.K. Mishra, Principal, College of Pharmaceutical Sciences, Puri, Odisha for providing a proper platform for carrying out this work.

\section{REFERENCES}

1. Arora S, Ali J, Ahuja A, Khar RK, Baboota S. Floating Drug Delivery Systems: A Review. AAPS PharmSciTech 6, 2005, 47.

2. N.K Jain. Gastro retentive Drug Delivery System. In: Garima C, Piyush G, Arvind K.B, Progress in Controlled and Novel Drug Delivery System, Vol, CBS Publishers, 2008, 76-97.

3. S.P Vyas, Roop K.Khar. Controlled Drug Delivery Concept and Advances, 1st Edn, M.K Jain Publisher for Vallabh Prakashan, 2002, 196-217.

4. Dhorajia Chintan R, Patel Jaymen M, Patel Kaushika S et al. An Overview on Bilayered Tablet Technology. World Journal of Pharmacy and Pharmaceutical Sciences. 2015; 4(4): 386-403.

5. Siva Sai Kiran B, Sambasiva Rao P, Raveendrababu G et al. Bilayer Tablets: A Review. International Journal of Pharmaceutical, Chemical and Biological Sciences. 2015; 5(3): 510-516.

6. Rubina Riechal C, Thirumoorthy N, Gopal rao M et al. Dual Release Tablet: Clinical Outcome and Evaluation. Journal of Chemical and Pharmaceutical Research. 2014; 6(9): 219-229.

7. Vishwakarma A.G, Mogal R.T, Pawar A.Y et al. Bilayer Tablet - A New Ways in Oral Drug Delivery System. International Journal of Pharma Tech Research. 2014; 6(5): 14161428.

8. Amrita Panda; Sukhadakulkarni; Ravi Tiwari, IJPRBS. 2013, 2(6), 69-80.

9. Lende Lathika K, Benerjee S.K, Gadhave M.V et al. Review on: Bilayer Floating Tablet. Asian Journal of Pharmaceutical Research and Development. 2013; 1(1): 31-39.

10. Mishra A, Bhatt G. Review: Bilayer Tablet and Evaluation. International Journal of Drug Research and Technology. 2013; 3(2): 21-30.

11. Noor Ahmed VH, Niharika G, Deepak P et al. Formulation Design, Characterisation and In-vitro Evaluation of Bilayered Tablets Containing Telmisartan and Hydrochlorthiazide. 
International Journal of Biopharmaceutics. 2013; 4(1): 1-9.

AJPHR is

Peer-reviewed

monthly

Rapid publication

Submit your next manuscript at

editor@ajphr.com / editor.ajphr@gmail.com 